\title{
Cardiovascular Adverse Outcomes as Challenges on Glycemic Variability Among Patients with Type 2 Diabetes on Intensive Insulin Therapy: The Role of Medical Nutrition Therapy with Automatic Snacking
}

\author{
Mercado-Asis $\mathbf{L B}^{1^{*}}$ and Lorenzo-Redoblado $\mathbf{Z G}^{2}$ \\ ${ }^{1}$ Section of Endocrinology and Metabolism, Department of Medicine, Faculty of Medicine and Surgery, University of \\ Santo Tomas, Manila, Philippines \\ ${ }^{2}$ Greencity Medical Center, Angeles City, Philippines
}

"Correspondence: Leilani B Mercado-Asis, Section of Endocrinology and Metabolism, Department of Medicine, Faculty of Medicine and Surgery, University of Santo Tomas, Manila, Philippines

Received on 13 July 2021; Accepted on 06 September 2021; Published on 13 September 2021

Copyright (C) 2021 Mercado-Asis LB, et al. This is an open access article and is distributed under the Creative Commons Attribution License, which permits unrestricted use, distribution, and reproduction in any medium, provided the original work is properly cited.

\begin{abstract}
The glycemic variability $(G V)$ is the fluctuation of the blood glucose $(B G)$ in relation to the daily mean $B G$ or mean glycosylated hemoglobin (HbAlc). BG oscillations can be influenced by the type of food and timing of intake, activity, psychological condition (fear of hypoglycemia), and systemic hormonal cross-talking between insulin and glucagon. Pharmacologically, these BG oscillations can be affected by the regulators of insulin secretion like sulfonylurea and insulin. The increase in GV with very high and very low BG excursions has been associated with the development of macrovascular and microvascular complications among type 2 diabetes mellitus (DM) patients. Increased mortality has been demonstrated in the past among elderly patients on intensive insulin therapy due to severe hypoglycemia. Prompt intake of glucose has obviously compromised glycemic control and worsens the GV. Automatic snacking (AS) as a part of medical nutrition therapy (MNT) is the provision of snacks $2 \mathrm{~h}$ after meals which are taken even in the absence of hunger. This review will showcase our published papers among patients with type $2 D M$ where AS was instituted to obtain long-term glycemic control and prevent the occurrence of fatal postprandial hypoglycemia. Although, further research is needed, AS is a promising dietary management to address GV in type 2 DM patients on intensive insulin therapy.
\end{abstract}

Keywords: glycemic variability, macrovascular and microvascular complications, hypoglycemia, automatic snacking, intensive insulin therapy, type 2 diabetes mellitus

Abbreviations: GV: glycemic variability; BG: blood glucose; HbA1c: glycosylated hemoglobin; DM: diabetes mellitus; AS: automatic snacking; MNT: medical nutrition therapy 


\section{Introduction}

Type 2 diabetes mellitus (DM) is a chronic metabolic disorder that requires control of blood glucose (BG) to prevent the development of both macrovascular and microvascular complications. The foundation of therapy is medical nutrition and exercise [1]. Glycemic control with pharmacologic therapy is instituted primarily to decrease insulin resistance and alleviate the relative insulin lack. Regulators of insulin secretion such as sulfonylurea, glinide, or insulin address the latter [2].

The control of glycemic status is mainly monitored through the measurement of fasting and postprandial BG [3]. The target BG values of 80-120 mg/dL preprandially, $140-180 \mathrm{mg} / \mathrm{dL}$ postprandially, and 6-7\% glycosylated hemoglobin (HbA1c) every 3 months were based on the landmark studies that have been shown to prevent the development of DM chronic complications $[4,5]$.

Recently, variability in the daily or monthly BG levels has been likewise linked to DM adverse chronic outcomes like neuropathy, retinopathy, and nephropathy [6-10]. The occurrence of fatal cardiovascular events like stroke, heart failure, and myocardial infarction has also been reported to be associated with glycemic variability (GV) [11-15]. However, it is the severe hypoglycemia occurring during nadirs of BG fluctuations mostly in the postprandial state that has shown to result in acute adverse cardiovascular events with increased morbidity and mortality [16-19]. Sun et al. [20] summarized the pathophysiologic mechanisms of these complications to oxidative stress, epigenetic changes, increased inflammatory cytokine production, increased platelet activation, and endothelial dysfunction.

In-hospital occurrence of severe hypoglycemia among type $2 \mathrm{DM}$ patients has been primarily observed in a setting of intensive insulin therapy [21]. The contributory factors have been identified as old age (> 65 years), hypoglycemia unawareness, advanced stage of DM, presence of diabetic kidney disease, and longer duration of insulin use [21-25]. In the report of Gehlaut et al. [26], type 2 DM patients on insulin exhibited higher GV scores (2.3 \pm 0.6$)$ as compared to those on oral medications $(1.8 \pm 0.7, \mathrm{P}=.017)$. Although the $\mathrm{HbA1c}$ variability has been a good predictor for the development of microvascular and macrovascular complications, it has been reported to be a weak predictor of hypoglycemia $[10,12,14,27]$. The combination of HbA1c and glycemic indices of GV like the coefficient of variation (CV), low blood glucose index (LBGI), and glycemic risk assessment diabetes equation (GRADE) have been reported to better discriminate this DM complication [6,27]. Motivational and better-adapted eating habits, tailoring individual therapy solutions, and de-escalating diabetes therapy were instituted and found to be effective in alleviating the significant marked decrease in BG [28]. The American Diabetes Association opt to employ a less stringent HbA1c level of $8 \%(64 \mathrm{mmol} / \mathrm{mol})$ for patients with a history of severe hypoglycemia, in whom the goal is difficult to achieve despite diabetes self-management education, appropriate glucose monitoring, and effective doses of multiple glucoselowering agents including insulin [29]. In some prompt intake of sugar-containing foods (glucose tablets, fruit juices, honey) has been advocated [30]. However, such approaches could compromise glycemic control and worsen and destabilize GV.

The objective of this article is to demonstrate how medical nutrition therapy (MNT) through automatic snacking (AS) could bridge a solution in the prevention of severe hypoglycemia among type 2 DM patients on intensive insulin therapy thereby stabilizing and decreasing the GV and sustaining excellent glycemic control.

\section{Glycemic Variability and Long-Term Adverse Outcomes}

Scientific publications have shown evidence that higher GV has an unfavorable effect on metabolic outcomes and increased the risk for acute and long-term DM adverse events. The table summarizes the association of increased GV with macrovascular and microvascular DM complications (Table 1). 


\begin{tabular}{|l|l|}
\hline Macrovascular complications & Microvascular complications \\
\hline $\begin{array}{l}\text { Associated with poor left ventricular (LV) } \\
\text { diastolic dysfunction and adverse left } \\
\text { ventricular remodeling. }\end{array}$ & $\begin{array}{l}\text { Independent risk factor for the deterioration } \\
\text { of renal function and positively correlated } \\
\text { with progression of DM chronic renal } \\
\text { disease. }\end{array}$ \\
$\begin{array}{l}\text { Increased risk of stroke, myocardial } \\
\text { infarction, and peripheral vascular disease. }\end{array}$ & $\begin{array}{l}\text { Independently associated with the risk of } \\
\text { DM retinopathy (DR) development and } \\
\text { inversely correlated with the severity of DR. }\end{array}$ \\
$\begin{array}{l}\text { Positively correlated with accelerated } \\
\text { progression of coronary atherosclerosis and } \\
\text { coronary artery spasm and negatively } \\
\text { correlated with coronary flow reserve. }\end{array}$ & $\begin{array}{l}\text { Potent predictor of diabetic peripheral } \\
\text { neuropathy (DPN) and negatively correlated } \\
\text { with the risk of painful DPN. }\end{array}$ \\
$\begin{array}{l}\text { Predicted the progression of heart failure and } \\
\text { mortality in ICU patients. }\end{array}$ & $\begin{array}{l}\text { Strongly associated with the degree of } \\
\text { severity of cardiovascular } \\
\text { autonomic } \\
\text { Significantly associated with increased } \\
\text { vascular calcification. }\end{array}$
\end{tabular}

Table 1: Macrovascular and microvascular complications in type 2 diabetes mellitus patients associated with glycemic variability.

In general, the elevation of HbA1c in patients with type $2 \mathrm{DM}$ increases the risk for microvascular and macrovascular complications [31-33]. Randomized controlled trials have shown that the treatment with anti-diabetic medication lowers HbA1c and the risks of these complications [34]. However, it remains debatable if the lowering of risks was fully attributed to the lowering of HbA1c, or from other factors, such as the pharmaceutical attributes of the antidiabetic compounds [35]. This matter was elaborated in the longitudinal study of type 2 DM patients by Rozing et al. [36]. The higher HbA1c levels one year after the diagnosis were associated with a higher risk of later diabetes-related morbidity and mortality. An increase in HbA1c during the first 6 years after diabetes diagnosis was associated with later microvascular complications (HR per $1.1 \mathrm{mmol} / \mathrm{mol}$ or $0.1 \%$ point increase in HbA1c per year; $95 \% \mathrm{CI}=1.14$; 1.05-1.24). However, change in HbA1c did not predict the aggregate outcome of any diabetes-related endpoint, allcause mortality, diabetes-related mortality, myocardial infarction, stroke, or peripheral vascular diseases [36].

$\mathrm{GV}$ is a parameter that has been gaining attention in the long-term prognostication for micro-and macrovascular complications and all-cause mortality in patients with type 2 DM. In the Rio de Janeiro Type 2 Diabetes (RIO-T2D) Cohort Study, high cardiovascular risk individuals with type 2 diabetes with a median follow-up of nearly 10 years were studied [37]. During the follow-up, 128 patients had cardiovascular events and 158 patients died from cardiovascular diseases. Furthermore, 152 had newly-developed or worsened diabetic retinopathy, 183 achieved the renal composite outcome (89 newly developed microalbuminuria and 91 deteriorated renal function), and 96 newlydeveloped or worsened peripheral neuropathy. The GV, particularly the 24-month parameters either estimated by $\mathrm{HbA} 1 \mathrm{c}$ or by fasting glycemia predicted all endpoints, except for retinopathy and peripheral neuropathy development or progression, and was a better predictor than the mean HbA1c [37]. On the other hand, in the recent cohort study of Yang et al. [38], microvascular disease risk increased with an increase in HbA1c variability measured as HbA1ccoefficient of variation. The heterogeneous finding in the risk of DM complications and HbA1c variability could have been attributed to overall glycemic control. The results of Yang et al. [38] showed that the associations of HbA1c variability and mean measures with microvascular disease risk in patients with baseline HbA1c $<7.5 \%(58 \mathrm{mmol} / \mathrm{mol})$ were stronger as compared with those in patients with baseline $\mathrm{HbAlc} \geq 7.5 \%(58 \mathrm{mmol} / \mathrm{mol})$. 


\section{Glycemic Variability, Hypoglycemia, and Cardiovascular Disease Outcomes Among Patients with Type 2 Diabetes Mellitus on Intensive Insulin Therapy}

The prevalence of hypoglycemia among patients with type $2 \mathrm{DM}$ on multiple daily insulin injections has been reported to be as high as $56.9 \%$ and the prevalence of unawareness of hypoglycemia was even higher at $75 \%$ [26, 39]. The increased vulnerability to hypoglycemia of patients with type 2 DM was ascribed to advanced age, duration of DM, duration of insulin use, and comorbidities like chronic kidney disease [40, 41]. The cognitive impairment and defective counter-regulatory responses to low blood sugar that develops with aging have made the elderly more vulnerable to acute and severe hypoglycemia [42, 43].

Considerable evidence both observational and landmark trials have demonstrated a consistent association between hypoglycemia and adverse cardiovascular outcomes in patients on intensive glycemic control $[4,5,44,45]$. The UKPDS results showed a higher incidence of hypoglycemia among those on intensive insulin treatment (1.8\%) vs the conventional $(0.7 \%)$ which increased to $2.5 \%$ when insulin treatment was continued for 6 years [5]. Although ample benefit on achieving the target $\mathrm{HbAlc}$ level has been obtained with intensive insulin therapy in the DCCT, ACCORD, and VADT studies, the occurrence of significant hypoglycemia offsets this benefit [4, 44, 45].

The GV in the setting of hypoglycemia among patients with type $2 \mathrm{DM}$ has been linked to age $>65$ years and insulin therapy as reported by Ishikawa et al. [16]. Of note, patients with lower blood sugar variability had a significantly lower hypoglycemia risk ( $<$ 0.0001). In the recent publication of Takeishi et al. [46], the mortality rate of 10\% among type 2 DM patients with infections admitted in non-intensive care units has been found to be not due to reactive inflammatory markers, vital signs, and bacteremia. The death rate increased by $266 \%$ (odds ratio [OR] 2.66, 95\% confidence interval [95\% CI] 1.22-5.83; P = 0.0006) when hypoglycemia coexists with GV [44]. Interestingly, Hanna et al. [47] demonstrated that among adult type 2 DM patients admitted to an ICU, high hospital mortality was associated with high GV irrespective of the blood sugar level, hypoglycemia occurrence, and premorbid glycemic control.

In the study of Battelino et al. [48] on glucose variability, hypoglycemia occurs mostly in the postprandial state. To counteract the postprandial hypoglycemia among elderly type 2 DM patients on intensive insulin therapy, the Hba1c goal was made less stringent, and, in general, patients have been advised to take glucose during hypoglycemic attacks $[29,30]$. Unfortunately, such measures may lead to compromised glycemic control and worsen glycemic lability.

\section{Medical Nutrition Therapy Through Automatic Snacking Bridging a Solution to Glycemic Variability and Severe Hypoglycemia}

Automatic snacking (AS) is a dietary management approach our group has developed initially to counteract only the hypoglycemic episodes occurring postprandially. In the dietary management approach with AS, there are 3 snacks to be taken $2 \mathrm{~h}$ after each main meal even when the patients are not hungry. The calories for the snacks are included in the $24 \mathrm{~h}$ calorie requirement of the patient (Figure 1). The approach is more preventive than reactionary to hypoglycemic episodes among patients either on sulfonylurea or insulin therapy that occurs in the postprandial period (Figure 2) [49-51]. Its long-term advantage in improving and stabilizing glycemic control has recently been reported [52]. Of note, with the AS dietary approach eating additional calories, as is customarily happens in conventional diet prescription, to offset the hypoglycemic episode is also prevented.

AS was first prescribed among patients with type $2 \mathrm{DM}$ on sulfonylurea (gliclazide), both AS and conventional diet groups showed improvement in the HbA1c but the AS group demonstrated greater HbA1c reduction. Noteworthy is the frequency of hypoglycemia in the AS group was statistically lesser than the conventional group [49]. A follow-up study yielded comparative results among type 2 DM patients on intensive insulin therapy for over 12 months with a cumulative reduction of $18 \%$ in the HbA1c level and with the absence of significant hypoglycemic episodes [50]. 
Our succeeding reports among type 2 diabetic patients on intensive insulin therapy (insulin 70/30 twice daily and premeal fast rapid insulin $3 \mathrm{x}$ a day, +/- glargine) in an outpatient setting have shown that AS consistently prevented the occurrence of severe hypoglycemia, and achieving the target Hbalc goal of about 7\% and below in 3-6 months after initiating the insulin regimen [50, 51]. In our recent publication on long-term (median 12 years, range 7-22 years) evaluation of patients with type $2 \mathrm{DM}$ on intensive insulin therapy in the outpatient setting, the event rates for an acute coronary event, stroke, and dialysis were negligible $(0.001,0.009,0.002$ per person-year, respectively) [52]. There was no blindness and amputation observed during the course of follow-up. The HbA1c levels decreased significantly from a mean $(\mathrm{SD})$ of $8.5+1.86$ from diagnosis to $7.83+1.71$ at last follow-up $(\mathrm{p}=0.00)$. After a median follow-up of 12 years (7-22 years), excellent glycemic control was sustained with an $\mathrm{HbAlc}$ of $\leq 7 \%$ and $\leq 8 \%$ in $32 \%$ and $45 \%$ of patients, respectively. Of note, there was no significant hypoglycemia observed during the long-term follow-up period [52]. Although the studies were not designed to investigate GV, the clinical course of the patients with sustained glycemic control, the negligible occurrence of microvascular and macrovascular DM complications, and the absence of significant hypoglycemia on a long-term basis are reflective of stable glycemic status.

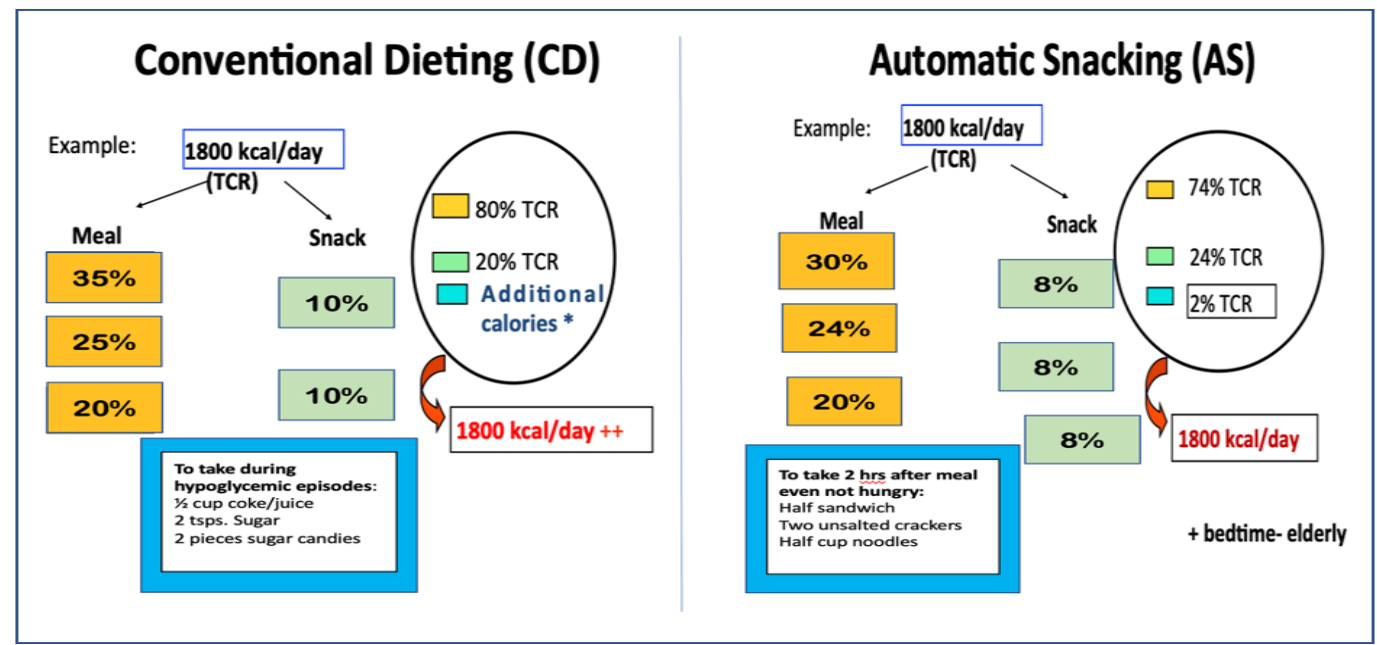

Figure 1: Sample meal calorie distribution in conventional dieting $v s$ automatic snacking.

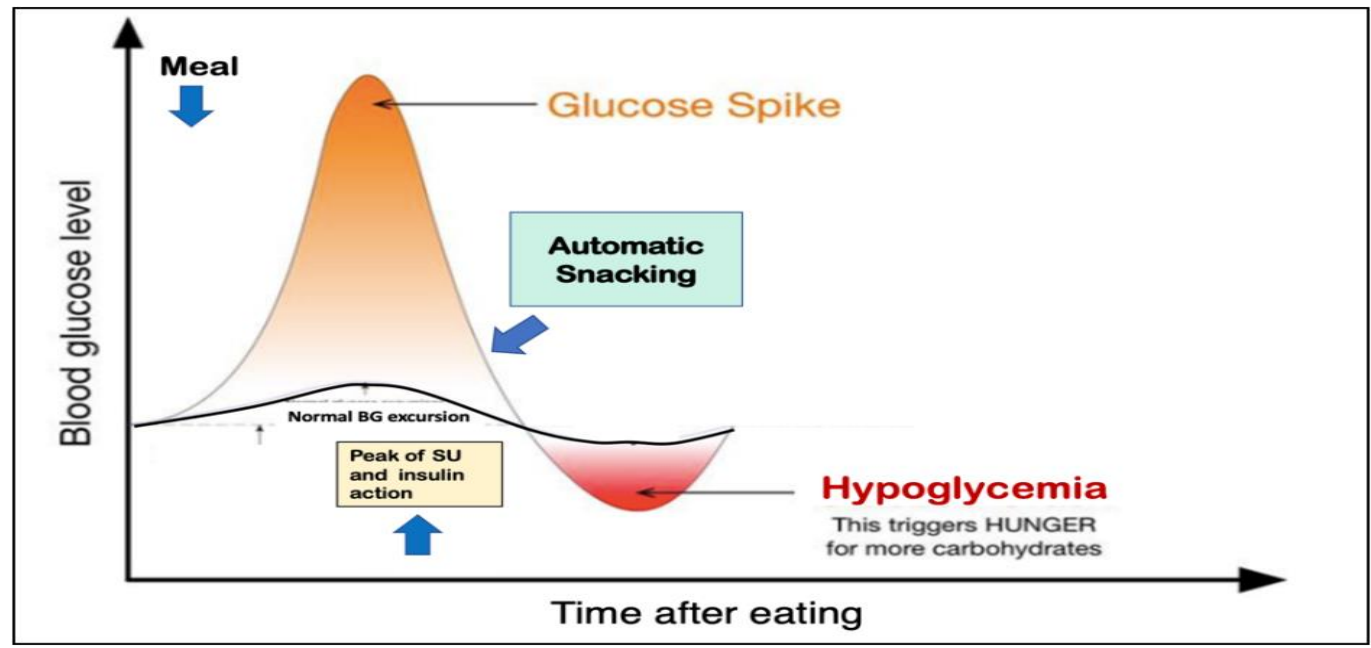

Figure 2: Schematic diagram depicting when automatic snacking is instituted to prevent hypoglycemia in type 2 diabetes mellitus patients on sulfonylurea (SU) and insulin therapy. BG: blood glucose.

To demonstrate that AS prevents hypoglycemia among admitted type 2 DM patients on intensive insulin therapy, we randomized 24 patients admitted in the medical or surgical ward to AS and conventional dietary management. The table shows that the baseline characteristics of the subjects on both arms were not statistically different (Table 2). The 
patients in both groups were able to reach the target postprandial capillary blood glucose (CBG) (140-180 mg/dL). However, those in the AS group had a statistically greater reduction in the CBG level (47\%) from baseline compared to those receiving a conventional diet $(34 \%, \mathrm{p}=0.04)$ (Figure 3). Furthermore, $100 \%$ of the patients in the AS group reached the goal in a shorter time, 1.2 days earlier, than those in the conventional diet regimen (Figure 4 and 5). Most noteworthy was the statistically lower incidence of hypoglycemia among patients in the AS group (8.3\%) compared to those in the conventional diet regimen $(60 \%)$. The latter group experienced severe hypoglycemia $(40 \mathrm{mg} / \mathrm{dL})$ which was not observed in the patients receiving AS (Figure 6).

\begin{tabular}{|l|l|l|l|}
\hline Characteristics & Conventional diet n= 12 & Automatic snacking n=12 & $\boldsymbol{p}$ value \\
\hline Age (year) & $58.7 \pm 13.7$ & $56.8 \pm 7.9$ & $0.18(\mathrm{NS})$ \\
\hline Sex & $5(30 \%)$ & $6(50 \%)$ & \\
\hline Male & $7(70 \%)$ & $6(50 \%)$ & \\
\hline Female & $22.8 \pm 1.61$ & $23.6 \pm 0.39$ & $0.78(\mathrm{NS})$ \\
\hline BMI kg/m ${ }^{2}, \mathrm{x}$ & $8.92 \pm 6.64$ & $8.6 \pm 2.27$ & $0.32(\mathrm{NS})$ \\
\hline Mean duration of diabetes (year) & $8.0 \pm 0.75$ & $7.9 \pm 0.39$ & $0.28(\mathrm{NS})$ \\
\hline HbA1c $(\%)$
\end{tabular}

Table 2: Baseline characteristics of type 2 diabetes mellitus patients on conventional diet $v s$ automatic snacking.

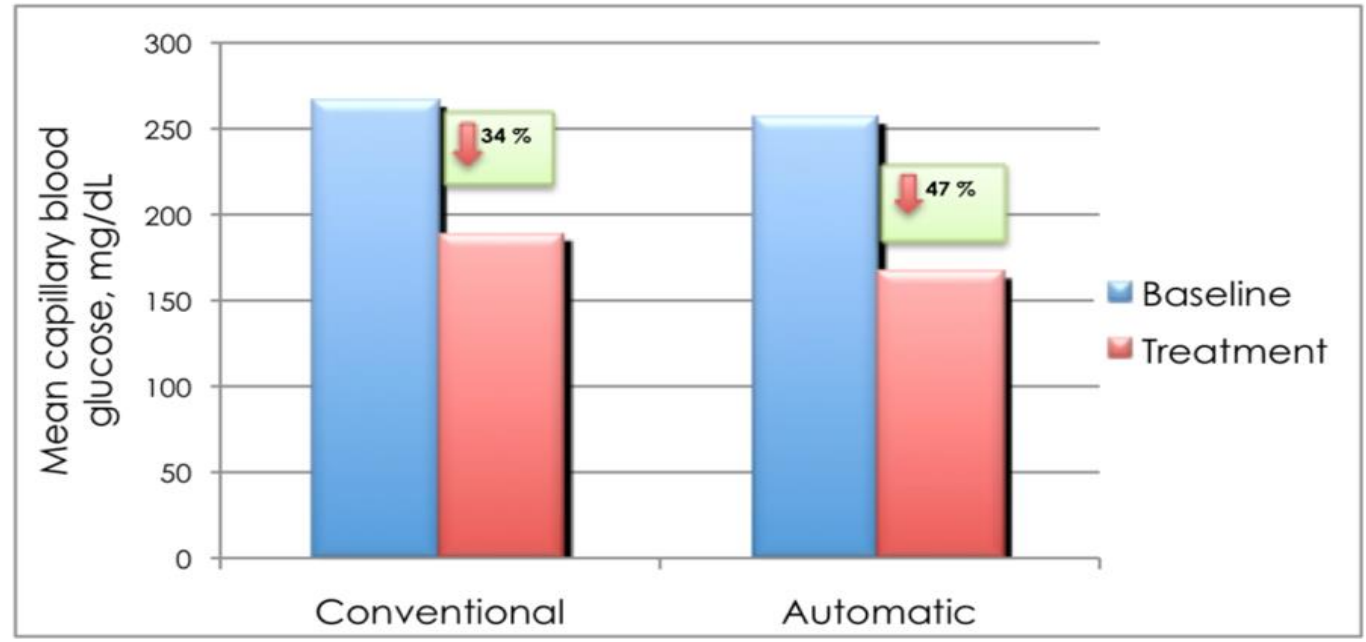

Figure 3: Mean change in the capillary blood glucose among type 2 diabetes mellitus patients on intensive insulin therapy receiving automatic snacking or conventional diet.

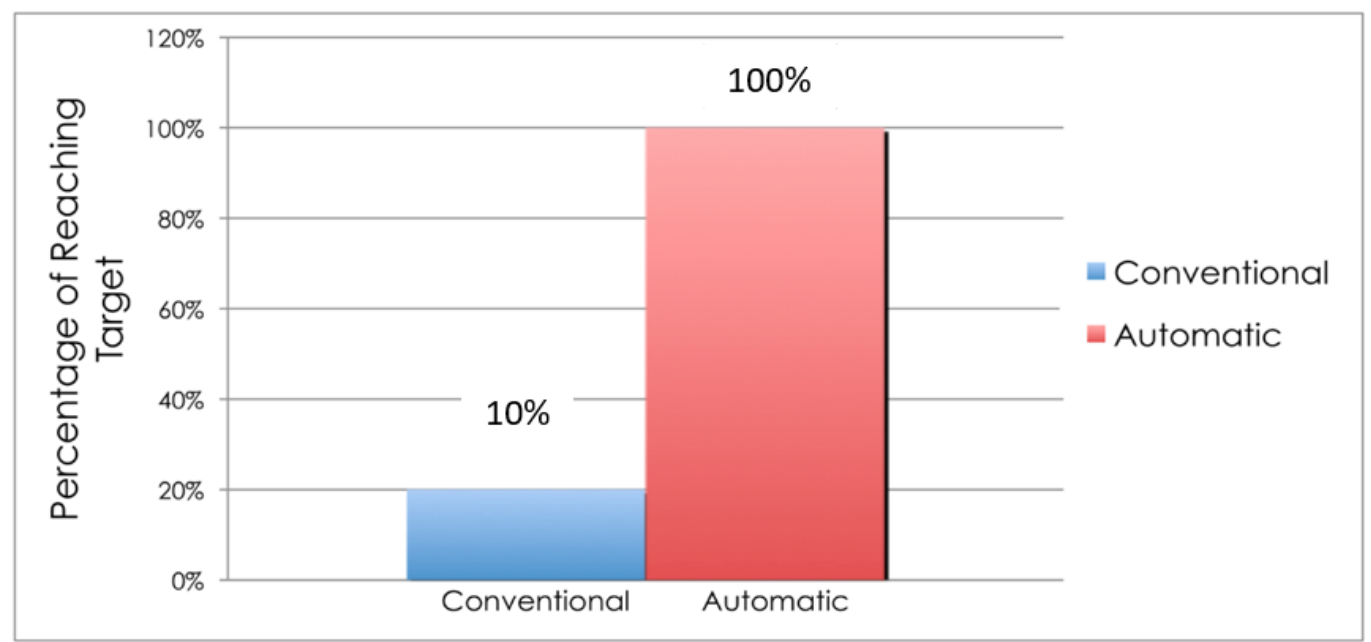

Figure 4: Percentage reaching glycemic target (140-180 mg/dL) among type 2 diabetes mellitus patients on intensive insulin therapy receiving automatic snacking or conventional diet. 


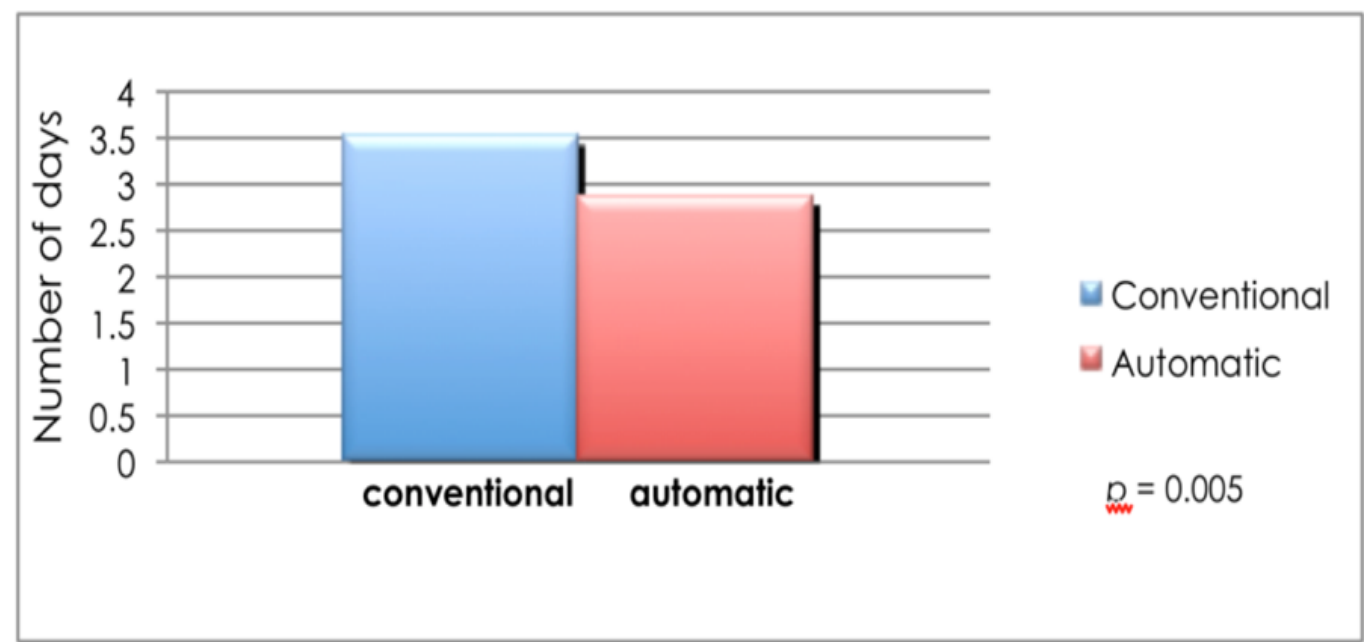

Figure 5: Mean time to reach target blood glucose among type 2 diabetes mellitus patients on intensive insulin therapy receiving automatic snacking or conventional diet.

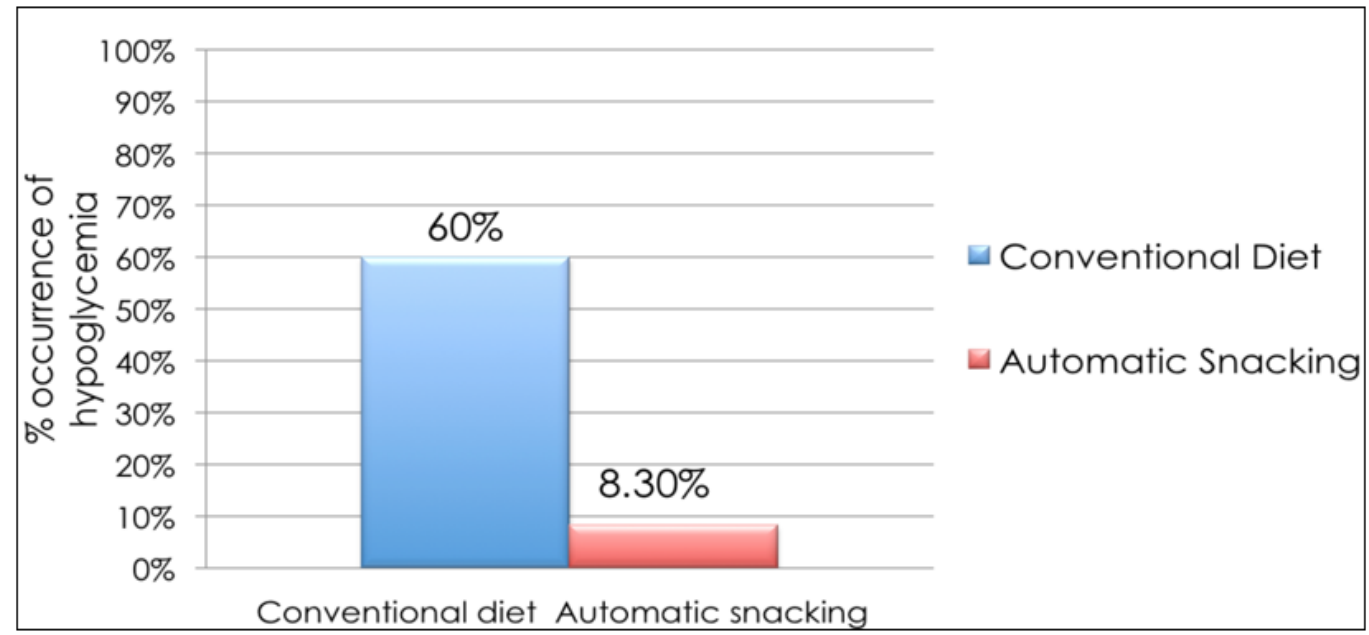

Figure 6: Occurrence of hypoglycemia (\%) among type 2 diabetes mellitus patients on intensive insulin therapy receiving automatic snacking or conventional diet.

\section{Insight and Conclusion}

The growing evidence that GV is a significant contributory factor in the development of DM complications post a big challenge to the care of type $2 \mathrm{DM}$ patients. It is not enough that the HbA1c target is attained. Glycemic control must be achieved without the occurrence of severe hypoglycemia especially in patients on intensive insulin therapy. To date, measures are geared towards blood sugar control but not on stabilizing GV.

MNT through AS is a dietary approach designed to address postprandial hypoglycemia. Although further study must be done to elaborate its role in controlling GV, our initial investigations on AS suggest that blood sugar excursion was rendered stable and low. Most importantly, severe hypoglycemia was prevented, thus sustaining the appropriate HbA1c target regardless of age.

\section{References}

1. Diabetes Control and Complications Trial Research Group, Nathan DM, Genuth S, et al. The effect of intensive treatment of diabetes on the development and progression of long-term complications in insulindependent diabetes mellitus. N Engl J Med. 1993;329(14):977-86. 
2. American Diabetes Association. Standards of medical care. Diabetes Care. 2021;44(Suppl 1):S15-S33.

3. American Diabetes Association. Standards of medical care. Diabetes Care. 2021;44 (Suppl 1):S73-S84.

4. Diabetes Control and Complications Trial Research Group. The relationship of glycemic exposure (HbA1c) to the risk of development and progression of retinopathy in the diabetes control and complications trial. Diabetes. 1995;44(8):968-83.

5. Genuth S, Eastman R, Kahn R, et al. Implications of the United Kingdom prospective diabetes study. Diabetes Care. 2003;26(Suppl 1):S28-S32.

6. Ceriello A, De Cosmo S, Rossi MC, et al. Variability in HbA1c, blood pressure, lipid parameters and serum uric acid, and risk of development of chronic kidney disease in type 2 diabetes. Diabetes Obes Metab. 2017;19(11):1570-578.

7. Christensen MMB, Hommel EE, Jørgensen ME, et al. Glycemic variability and diabetic neuropathy in young adults with type 1 diabetes. Front Endocrinol. 2020;11:644.

8. Lee $\mathrm{C}$, Chen $\mathrm{C}, \mathrm{Wu} \mathrm{M}$, et al. The variability of glycated hemoglobin is associated with renal function decline in patients with type 2 diabetes. Ther Adv Chronic Dis. 2020;11:1-10.

9. Lu J, Ma X, Zhou J, et al. Association of time in range, as assessed by continuous glucose monitoring, with diabetic retinopathy in type 2 diabetes. Diabetes Care. 2018;41(11):2370-376.

10. Chiu W, Lai Y, Cheng B, et al. HbA1c variability is strongly associated with development of macroalbuminuria in normal or microalbuminuria in patients with type 2 diabetes mellitus: A six-year followup study. BioMed Res Int. 2020:7462158.

11. Yokota S, Tanaka H, Mochizuku Y, et al. Association of glycemic variability with left ventricular diastolic function in type 2 diabetes mellitus. Cardiovasc Diabetol. 2019;18(1):166.

12. Lee DY, Han K, Park S et al. Glucose variability and the risks of stroke, myocardial infarction, and all-cause mortality in individuals with diabetes: retrospective cohort study. Cardiovasc Diabetol. 2020;19(1):144.

13. Li S, Tang X, Lou Y, et al. Impact of long-term glucose variability on coronary atherosclerosis progression in patients with type 2 diabetes: A 2.3 year follow-up study. Cardiovasc Diabetol. 2020;19(1):146.

14. Yang CD, Shen Y, Lu L, et al. Visit-to-visit HbA 1c variability is associated with in-stent restenosis in patients with type 2 diabetes after percutaneous coronary intervention. Cardiovasc Diabetol. 2020;19(1):133.

15. Nishi T, Saito Y, Kitahira H, et al. Coronary flow reserve and glycemic variability in patients with coronary artery disease. Intern Med. 2021;60(8):1151-158.

16. Ishikawa T, Koshizaka M, Maezawa Y, et a;. Continuous glucose monitoring reveals hypoglycemia risk in elderly patients with type 2 diabetes mellitus. J Diabetes Investig. 2018;9(1):69-74.

17. Ikeda Y, Kubo T, Oda E, et al. Incidence rate and patient characteristics of severe hypoglycemia in treated type 2 diabetes mellitus patients in Japan: Retrospective diagnosis procedure combination database analysis. J Diabetes Investig. 2018;9(4):925-36.

18. Kuroda N, Kusunoki Y, Osugi K, et al. Relationships between time in range, glycemic variability including hypoglycemia and types of diabetes therapy in Japanese patients with type 2 diabetes mellitus: Hyogo diabetes hypoglycemia cognition complications study. J Diabetes Invetig. 2021;12(2):244-53.

19. International Hypoglycemia Study Group. Hypoglycaemia, cardiovascular disease, and mortality in diabetes: epidemiology, pathogenesis, and management. Lancet Diabetes Endocrinol. 2019;7(5):385-96. 
20. Sun B, Luo Z, Zhou J. Comprehensive elaboration of glycemic variability in diabetic macrovascular and microvascular complications. Cardiovasc Diabetol. 2021;20:9.

21. Heller SR, Peyrot M, Oates SK, et al. Hypoglycemia in patient with type 2 diabetes treated with insulin: It can happen. BMJ Open Diabetes Res Care. 2020;8(1):e001194.

22. Khunti K, Alsifri S, Aronson R et al. Rates and predictors of hypoglycaemia in 27585 people from 24 countries with insulin-treated type 1 and type 2 diabetes: the global HAT study. Diabetes Obes Metab. 2016;18(9):907-15.

23. Klimontov VV, Myakina NE. Glucose variability indices predict the episodes of nocturnal hypoglycemia in elderly type 2 diabetic patients treated with insulin. Diabetes Metab Syndr. 2017;11(2):119-24.

24. Mangrola D, Cox C, Furman AS, et al. Self blood glucose monitoring underestimates hyperglycemia and hypoglycemia as compared to continuous glucose monitoring in type 1 and type 2 diabetes. Endocr Pract. 2018;24(1):47-52.

25. Peene B, D’Hooge D, Vandebrouck T, et al. Patient-reported frequency, awareness and patient-physician communication of hypoglycaemia in Belgium. Acta Clin Belg. 2014;69(6):439-45.

26. Gehlaut RR, Dogbey GY, Schwartz FL, et al. Hypoglycemia in type 2 diabetes--more common than you think: a continuous glucose monitoring study. J Diabetes Sci Technol. 2015;9(5):999-1005.

27. Chandran SR, Tay WL, Lye WK, et al. Beyond HbA1c: comparing glycemic variability and glycemic indices in predicting hypoglycemia in type 1 and type 2 diabetes. Diabetes Technol Ther. 2018;20(5):353-62.

28. Kloos C, Burghardt K, Müller UA, et al. Reduction of severe hypoglycaemia in people with type 2 diabetes after a structured inpatient intervention. Exp Clin Endocrinol Diabetes. 2021;129(8):587-92.

29. American Diabetes Association. Glycemic targets: Standards of medical care in diabetes- 2019. Diabetes Care. 2019;42(Suppl 1):S61-S70.

30. Hypoglycemia. Patient Care \& Health Information:Diseases \& Conditions.

31. Gerstein HC, Pogue J, Mann JF, et al. The relationship between dysglycaemia and cardiovascular and renal risk in diabetic and non-diabetic participants in the HOPE study: a prospective epidemiological analysis. Diabetologia. 2005;48(9):1749-755.

32. Gerstein HC, Islam S, Anand S, et al. Dysglycaemia and the risk of acute myocardial infarction in multiple ethnic groups: an analysis of 15,780 patients from the INTERHEART study. Diabetologia. 2010;53(12):2509-517.

33. Cavero-Redondo I, Peleteiro B, Alvarez-Bueno C, et al. Glycated haemoglobin A1c as a risk factor of cardiovascular outcomes and all-cause mortality in diabetic and non-diabetic populations: a systematic review and meta-analysis. BMJ Open. 2017;7(7):e015949.

34. Intensive blood-glucose control with sulphonylureas or insulin compared with conventional treatment and risk of complications in patients with type 2 diabetes (UKPDS 33). UK Prospective Diabetes Study (UKPDS) Group. Lancet. 1998;352(9131):837-53.

35. Skrha J, Soupal J, Skrha Jr J, et al. Glucose variability, HbA1c and microvascular complications. Rev Endocr Metab Disord. 2016;17(1):103-10.

36. Rozing MP, Moller A, Aabenhus R, et al. Changes in HbA1c during the first six years after the diagnosis of type 2 diabetes mellitus predict long-term microvascular outcomes. PLoS ONE. 2019;14(11):e0225230. 
37. Cardoso CRL, Leite NC, Moram CBM, et al. Long-term visit-to-visit glycemic variability as predictor of micro- and macrovascular complications in patients with type 2 diabetes: The Rio de Janeiro Type 2 Diabetes Cohort Study. Cardiovasc Diabetol. 2018;17(1):33.

38. Yang C, Su P, Hung J, et al. Comparative predictive ability of visit-to-visit HbA1c variability measures for microvascular disease risk in type 2 diabetes. Cardiovasc Diabetol. 2020;19(1):105.

39. Zick R, Petersen B, Richteer M, et al. Comparison of continuous blood glucose measurement with conventional documentation of hypoglycemia in patients with type 2 diabetes on multiple daily insulin injection therapy. Diabetes Technol Ther. 2007;9(6):483-92.

40. Heller SR, Pratley RE, Sinclair A, et al. Glycaemic outcomes of an individualized treatment approach for older vulnerable patients: A randomized, controlled study in type 2 diabetes mellitus (IMPERIUM). Diabetes Obes Metab. 2018;20(1):148-56.

41. Schloot NC, Haupt A, Schutt M, et al. Risk of severe hypoglycemia in sulfonylurea-treated patients from diabetes centers in Germany/Austria: How big is the problem? Which patients are at risk? Diabetes Metab Res Rev. 2016;32(3):316-24.

42. Cukierman-Yaffe T, Gerstein HC, Williamson JD, et al. Relationship between baseline glycemic control and cognitive function in individuals with type 2 diabetes and other cardiovascular risk factors. Diabetes Care. 2009;32(2):221-26.

43. Huang ES, Laiteerapong N, Liu JY, et al. Rates of complications and mortality in older patients with diabetes mellitus: the diabetes and aging study. JAMA Intern Med. 2014;174(2):251-58.

44. ACCORD Study Group. Effects of intensive glucose lowering in type 2 diabetes. N Engl J Med. 2008;358(24):2545-559.

45. Duckworth W, Abraira C, Moritz T, et al. Glucose control and vascular complications in Veterans with type 2 diabetes. N Engl J Med. 2009;360(2):129-39.

46. Takeishi S, Mori A, Hachiya H, et al. Hypoglycemia and glycemic variability are associated with mortality in non-intensive care unit hospitalized infectious disease patients with diabetes mellitus. J Diabetes Investig. 2015;7(3):429-35.

47. Hanna M, Balintescu A, Glassford N, et al. Glycemic lability index and mortality in critically ill patients-A multicenter cohort study. Acta Anaesthesiol Scand. 2021;00:1-9.

48. Battelino T, Danne T, Bergenstal RM, et al. Clinical targets for continuous glucose monitoring data interpretation: Recommendations from the international consensus on time in range. Diabetes Care. 2019;42(8):1593-603.

49. Mercado-Asis L B. Single blinded randomized clinical trial on comparison of glycemic control and episodes of hypoglycemia in type 2 diabetes mellitus patients on conventional diet versus automatic snacking. Santo Tomas J Med. 2005;52(4):140-46.

50. Laplano NE, Quiambao DAM, Uy J, et al. Combination insulin therapy with pre-mixed intermediate/rapidacting insulin (70/30) and insulin lispro mimicking physiologic insulin secretion: optimal glycemic treatment with sustainability of control in type 2 diabetic patients. Phil J Int Med. 2010;47(3):93-97.

51. Lorenzo ZG, Mercado-Asis LB. Automatic snacking prevents hypoglycemia among outpatient type 2 diabetic patients on intensive insulin therapy. Phil J Int Med. 2011;49:57-60.

52. Valdez MNR, Mercado-Asis LB. Long term evaluation of intensive insulin therapy in patients with type 2 diabetes mellitus. Series Endo Diab Met. 2020;2(3):88-94. 